\title{
Endocrine Regulation Of Cognition And Neuroplasticity: Our Pursuit To Unveil The Complex Interaction Between Hormones, The Brain And Behaviour
}

\author{
Liisa A.M. Galea*, Kristina A. Uban ${ }^{+}$, Jonathan R. Epp ${ }^{+}$, Susanne Brummelte ${ }^{+}$, \\ Cindy K. Barha ${ }^{+}$, Wendy L. Wilson ${ }^{+}$, Stephanie E. Lieblich ${ }^{+}$, Jodi L. Pawluski ${ }^{+}$
}

Department of Psychology, Program in Neuroscience, University of British Columbia

*Please send correspondence to:

Liisa Galea, Ph.D.

Department of Psychology

The University of British Columbia

2136 West Mall

Vancouver, BC

V6T1Z4

phone:(604)822-6536

fax:(604)822-6923

email: lgalea@psych.ubc.ca

lab:(604) 822-3941

website: www.psych.ubc.ca/ Igalea

${ }^{+}$all these authors contributed equally 


\begin{abstract}
Gonadal and stress hormones modulate neuroplasticity and behaviour. This review focuses on our findings over the past decade on the effects of estrogens and androgens on hippocampal neurogenesis, hippocampus-dependent learning and memory and the effects of reproductive experience in the rodent. Briefly, evidence suggests that acute estradiol initially enhances and subsequently suppresses cell proliferation in the dentate gyrus of adult female rodents, but may have limited effects in male rodents. Intriguingly, repeated exposure to estradiol modulates hippocampal neurogenesis and cell death in adult female, but not male, rodents. Furthermore, testosterone and dihydrotestosterone upregulate hippocampal neurogenesis (via cell survival) in adult male rodents. We have found that estradiol can dose-dependently affect different brain regions that are involved in working memory (prefrontal cortex and hippocampus), reference memory (hippocampus) and conditioned place preference (amygdala). Pregnancy and motherhood differentially regulate adult hippocampal neurogenesis in the adult female rodent, with primiparous rats displaying lower levels of hippocampal cell proliferation and survival after parturition but better spatial working memory after weaning. These studies and others demonstrate that the female brain is organized differently and responds to steroid hormones differently than the male brain. It is of the upmost importance to investigate the effects on neuroplasticity and behaviour in both the male and the female, particularly when modelling diseases that exhibit sex differences in the incidence, etiology or treatment. This is especially important if we are to use our knowledge of how adult neurogenesis is regulated to develop strategies to repair neuron loss in neurodegenerative diseases such as Alzheimer's disease and depression that exhibit clear sex differences.
\end{abstract}


Over the past few years the Behavioural Neuroendocrinology laboratory in the Department of Psychology at the University of British Columbia has focused on investigating the effects of hormones on brain and behaviour. Hormones are chemical messengers released from endocrine glands that travel, typically through the blood stream, to target sites at distant locations. While, there are many classes of hormones: steroid, peptide, monoamine and lipid-based hormones, our laboratory focuses on the influence of the steroid hormones: androgens, estrogens and glucocorticoids. In the classical model of steroid action, gonadal hormones exert their genomic effects by crossing through the cell membrane and acting on receptors within the cytoplasm or nucleus to regulate gene expression. However, steroids can also exert non-genomic effects that act on receptors in the cell membrane. The powerful effects of hormones are evidenced by major life events, such as puberty, pregnancy and menopause, which are in part orchestrated by these chemical messengers. Steroid hormones influence adult neurogenesis, electrophysiological and structural properties in the brain, regulate gene transcription (when bound to their receptor) and reproductive and non-reproductive behaviour (Lee \& McEwen, 2001). My research program investigates how steroid hormones influence cognition, emotion and neuroplasticity. The three main areas of research in my laboratory include: 1) Hormonal control of neurogenesis; 2) Hormonal control of learning and memory; and 3) The influence of reproductive experience on brain and behaviour. Although these areas appear diverse there are common questions that link them including: What is the behavioural function of adult neurogenesis? How do hormones regulate cognition, mood and morphology of the brain? In this review we will discuss these areas of research and the major findings from our laboratory.

Hormonal control of Adult Neurogenesis in the Hippocampus

Adult neurogenesis exists in most mammalian species, including humans, in two main areas: the subventricular zone (new cells migrate to the olfactory bulbs) and the dentate gyrus of the 
hippocampus (Gould, 2007). The subgranular zone in the dentate gyrus contains progenitor cells which maintain the ability to divide and the majority of the resulting daughter cells become mature granule cells. Many of these new neurons die within two weeks of being produced (Cameron, Woolley, McEwen \& Gould, 1993) but exposure to different treatments, including steroid hormones, can either enhance or suppress survival of these new neurons (Barker \& Galea, 2008; Epp, Spritzer \& Galea, 2007; Ormerod, Lee \& Galea, 2004; Spritzer \& Galea, 2007). My laboratory has studied the effects of steroid hormones on adult neurogenesis in the dentate gyrus since 1997. We are interested in not only how steroid hormones regulate neurogenesis in the hippocampus but whether or not steroid hormones alter learning and memory via their effects on neurogenesis. However prior to describing our findings it is important to clarify characteristics of neurogenesis.

Neurogenesis is comprised of at least four processes; cell proliferation, differentiation, migration and cell survival (see Figure 1). Factors that affect cell proliferation are those that either suppress or induce mitosis in precursor cells while factors that affect cell survival either promote or prevent the differentiation and/or maturation of cells into mature neurons. Thus, the number of new neurons could be increased not only by increasing cell proliferation but also by enhancing the survival of new neurons, independent of affecting cell proliferation. For example, chronic exposure to antidepressants upregulates cell proliferation but has no independent effect on cell survival (Malberg, Eisch, Nestler, \& Duman, 2000), while exposure to an enriched environment upregulates cell survival, but has no effect on cell proliferation (Olson, Eadie, Ernst, \& Christie, 2006). Understanding the regulatory mechanisms of both cell proliferation and survival are important in neurogenesis research. Evidence suggests that adult neurogenesis in the hippocampus is associated with the mnemonic and 'emotional' (as related to depression) properties of the hippocampus (Thomas \& Peterson, 2008; Winocur, Wojtowicz, Sekeres, Snyder \& Wang, 2006). Many factors affect adult neurogenesis in the 
hippocampus, including gonadal and adrenal steroid hormones (for review see: Mirescu \& Gould, 2006; Barha, Barker, Brummelte, Epp, \& Galea, in press; Galea 2008). Importantly, the hippocampus contains many steroid receptors including glucocorticoid, estrogen and androgen receptors (McEwen, 1994; Weiland, Orikasa, Hayashi, \& McEwen, 1997; Tabori et al., 2005), which suggests that gonadal and adrenal hormones may directly modulate hippocampal neurogenesis in adulthood. In addition, there are well-known sex differences in the effects of steroid hormones and stress on hippocampal plasticity (Galea et al., 1997; Shors, 2004; Woolley \& McEwen 1993), hippocampus-dependent learning and memory (Galea, Kavaliers \& Ossenkopp, 1996; Shors, 2004) and the incidence of depression (Gutiérrez-Lobos, Scherer, Anderer, \& Katschnig, 2002). Given the data on gonadal hormone modulation of hippocampus structure and function, it is not surprising that gonadal hormones affect neurogenesis in the adult hippocampus.

There are two primary methods for identifying newly synthesized cells: thymidine analogues (such as 5-bromo-2-deoxyuridine (BrdU)) that are incorporated into the cell's DNA during the synthesis stage of mitosis or endogenous markers, such as Ki-67, which labels actively dividing cells at all stages of mitosis except for $\mathrm{G}_{0}$. The use of BrdU is the most popular in the literature but is not without some criticisms and caveats for use (see excellent review by Taupin, 2007). The number of times each of these thymidine analogues is administered, the timing between injections, the dose used and when these analogues are given relative to treatment can drastically influence the findings and are often different across studies making it increasingly difficult to directly compare results. A single injection of BrdU followed by perfusion up to $2 \mathrm{~h}$ later can be used to determine the number of progenitor cells synthesizing DNA, while perfusion after completion of one cell cycle (approximately 24.7 $\mathrm{h}$ in the adult rat: Cameron and McKay, 2001) allows for examination of daughter cells produced and finally perfusion any time after $25 \mathrm{~h}$ will result in investigating the survival of these new daughter 
cells. Depending on the time point of perfusion for cell survival, new cells can be phenotyped using endogenous markers such as doublecortin (immature neuronal marker: labels cells approximately 1-14 d old) or NeuN (mature neuronal marker: labels cells beginning approximately 2 weeks old). Multiple injections decrease the accuracy of the estimation of birth date of any particular cell and will ultimately label a heterogeneous population of cells. Problems with multiple injections arise if an experimental treatment differentially affects cell proliferation and cell survival, and thus multiple injections of BrdU can prevent accurate description of treatment effects. BrdU-labeling after either single or multiple injections can become ‘diluted’ if BrdU-labeled cells continue to divide. Cells containing ${ }^{3} \mathrm{H}-$ thymidine and BrdU, for example, are distinguishable from background for only 4-5 divisions after labeling (Stone, Miller \& Prescott, 1965; Prickaerts, Koopmens, Blokland, Scheepens, 2004). Furthermore thymidine analogues can be affected by a variety of factors that may not reflect real group differences such as dose or changes in the permeability of the blood-brain barrier (Taupin, 2007). The use of endogenous proteins rather than injected compounds allows researchers to avoid the major potential problems involved with the injection of DNA synthesis markers. However, one main drawback to using endogenous proteins alone is that the timeline of expression may be uncertain or very broad; doublecortin, for example, may be expressed anywhere from 1 to 14 or more days postdivision (Brown et al., 2003), and is also present in certain classes of putative neuronal progenitor cells (Kempermann, Jessberger, Stiner, \& Kronenberg, 2004). Such issues need to be considered, along with the questions of interest, prior to choosing the method of analysis of neurogenesis and the timing of injections (if given).

Androgens influence neurogenesis in adult male rodents

Few studies have investigated the effects of androgens on neurogenesis and neuroplasticity, however, the importance of androgen involvement is evident. Numerous studies have focused on the 
link between androgen levels and cognition, as decreased androgen levels are strongly correlated with a decline in cognitive performance (Moffat et al., 2002; Wolf \& Kirschbaum, 2002). Reductions in androgen levels are a common phenomenon in older males and have been linked to age-associated memory problems (see review, Janowsky, 2006). Furthermore additional evidence to support the role of androgen deprivation and cognitive processing is substantiated by studies involving gonadectomized rodents, hypogonadism, and androgen deprivation therapy. For example, castration of male rodents produces cognitive deficits in tasks such as object recognition, radial arm maze, T-maze, and inhibitory avoidance (Daniel, Winstauer, \& Moerschbaecher, 2003; Frye and Seliga, 2001; Kritzer, McLaughlin, Smirlis, \& Robinson, 2001; Spritzer, Gill, Weinberg \& Galea, 2008). Similarly, intra-hippocampal administration of flutamide, an androgen receptor (AR) antagonist, impairs performance in both water maze and inhibitory avoidance tasks (Edinger \& Frye, 2007). Studies examining prostate cancer patients undergoing androgen deprivation have found the same relationship with androgen deprivation related to cognitive impairments (see review by Nelson, Lee, Gamboa, \& Roth, 2008). In summary, circulating testosterone levels are linked to impaired cognitive performance in older males and one potential mechanism underlying these hormone-regulated changes could be via effects on adult neurogenesis within the hippocampus.

We have begun to explore the relationship between androgens and adult hippocampal neurogenesis. Ormerod and Galea (2003) found that the reproductive status of male meadow voles influenced cell survival, but not cell proliferation. Specifically, reproductively active males (with higher androgen levels) had increased cell survival in the dentate gyrus of the hippocampus compared to reproductive inactive males. Furthermore, hippocampal volumes are significantly larger in high testosterone versus low testosterone male voles (Galea, Perrot-Sinal, Kavaliers, \& Ossenkopp, 1999), and this difference could be a reflection of increased cell survival in the hippocampus (Ormerod \& 
Galea, 2003). Gonadectomized adult males had reduced cell survival in the dentate gyrus but there were no significant differences on cell proliferation compared to intact males (Kambo \& Galea, 2006; Spritzer \& Galea, 2007). Administration of either testosterone or its metabolite, dihydrotestosterone, was capable of enhancing cell survival, but had no significant effect on cell proliferation (Spritzer \& Galea, 2007). Because dihydrotestosterone increased neurogenesis, while estradiol (also a testosterone metabolite) did not, this suggests that this neurogenic activity is mediated through an androgendependent pathway. Furthermore, current studies in our laboratory are investigating the effects of androgens on neurogenesis in older male rats. Preliminary findings show reduced cell survival in older males compared to young adults and that thirty days of administration of dihydrotestosterone increased cell survival in the older males compared to aged-matched controls (Wilson \& Galea, unpublished findings). Ultimately, it appears that androgen involvement in neurogenesis is specific to cell survival with little to no effect on cell proliferation in the adult male hippocampus. Whether or not these androgen-mediated changes in hippocampal neurogenesis are related to changes in hippocampusdependent learning and memory are still not known.

\section{Estrogens influence hippocampal neurogenesis in adult male and female rodents}

The effects of estradiol on hippocampal neurogenesis in adult female rodents are beginning to be understood in the literature and we will briefly review literature from our laboratory on how estrogens influence cell proliferation and cell survival in the adult rodent. Previously, we found that short-term exposure to a high dose of estradiol increases, whereas exposure for 48 hours decreases cell proliferation in the dentate gyrus of ovariectomized adult female rats and voles (Ormerod \& Galea, 2001; Ormerod, Lee \& Galea, 2003). The estradiol-induced suppression of cell proliferation after 48 hours is mediated in part by adrenal steroids, as adrenalectomy eliminated, but did not reverse, the estradiol-induced suppression of cell proliferation in female rats (Ormerod et al., 2003). Interestingly, 
administration of high estradiol also increases cell proliferation in gonadectomised male rats but not to the same extent as seen in female rats, and there is no evidence of a suppression in cell proliferation at 48 hours (Pawluski, Lieblich, Wilson, unpublished results). Earlier work also demonstrated a sex difference across the seasons in cell proliferation with females having higher levels of cell proliferation than males during the non-breeding season (Galea \& McEwen, 1999). These findings support the contention that there are sex differences in the effects of gonadal hormones on cell proliferation (review see Galea, 2008).

There are three principle forms of estrogen: estrone, estradiol, and estriol. Estradiol is the most potent form of estrogen and is found at high levels in pre-menopausal women while estrone is the predominate form of estrogen in post-menopausal women (Rannevik et al., 1995). We recently found that an acute injection of estradiol or estrone rapidly increased cell proliferation in a dose-dependent manner in adult female rats. These different forms of estrogen increased cell proliferation rapidly, within 30 minutes, in ovariectomized adult females, possibly through non-classical, non-genomic mechanisms (Barha, Lieblich, \& Galea, submitted). Further we have recently shown that chronic treatment with estradiol for 15 days increases cell proliferation in ovariectomized adult female rats, but not in gonadectomised adult male rats, suggesting that repeated estradiol exposure may positively affect hippocampal cell proliferation in a sex-dependent manner (Barker \& Galea, 2008).

Recent studies have investigated the effects of chronic treatment with estradiol on cell survival, independent of cell proliferation, in both male and female rodents. Short-term treatment with estradiol on days 6-10 after BrdU injection enhances neurogenesis (via cell survival) in the dentate gyrus of adult male meadow voles (Ormerod, et al., 2004), demonstrating that estradiol can influence neurogenesis in the male rodent at least at a specific time point (during the axon extension phase). Repeated injections of estradiol for 15 consecutive days decreases the number of BrdU-labeled cells 
surviving in the dentate gyrus of ovariectomized adult female rats, but does not have an effect in castrated adult male rats (Barker \& Galea, 2008). Increasing the number of days males are exposed to estradiol from 15 days to 29 days still does not affect cell survival (Spritzer \& Galea, 2007). Interestingly, repeated administration of estradiol decreases overall cell death in the dentate gyrus of female, but not male, rats (Barker \& Galea, 2008). These findings show that adult female rats are more responsive to chronic administration of estradiol than male rats at least in terms of hippocampal neurogenesis and apoptosis (cell death). We are currently exploring the effects of chronic administration of other forms of estrogens on neurogenesis, cell death and cognition. Preliminary results suggest that 15 days of estradiol influence contextual fear conditioning in female, but not male, rodents, which is coincident with the findings on chronic estradiol and neurogenesis (Barker, Park \& Galea, unpublished data).

There are two known forms of the estrogen receptor (ER), ER $\alpha$ and ER $\beta$ (Koike, Sakai, \& Muramatsu, 1987; Kuiper, Enmark, Pelto-Huikko, Nilsson, \& Gustafsson, 1996). Both isoforms are located throughout the dentate gyrus of the hippocampus (Weiland et al. 1997; Herrick, Waters, Drake, McEwen, \& Milner, 2006) and are on progenitor cells within the subgranular zone (Isgor \& Watson 2005; Mazzucco, et al., 2006), suggesting that estrogens could influence hippocampal neurogenesis via activation of these receptors. We have recently shown that treatment with propyl-pyrazole triol, an ER $\alpha$ agonist, and with diarylpropionitrile, an ER $\beta$ agonist, increases cell proliferation in ovariectomized adult female rats, indicating that both ER $\alpha$ and ER $\beta$ are involved in the estradiol-induced enhancement of hippocampal cell proliferation (Mazzucco et al., 2006). Interestingly, neither the ER $\alpha$ nor the ER $\beta$ agonist increased cell proliferation to the same extent as estradiol alone. Administration of both agonists together decreased cell proliferation compared to estradiol, suggesting that estradiol may be influencing cell proliferation partially or completely through an alternative mechanism independent of 
ER $\alpha$ and ER $\beta$. For example, estradiol could potentially be acting via non-classical ERs, including the plasma-membrane-associated putative ER-X (Toran-Allerand et al., 2002). We are currently exploring other possible mechanisms through which estrogens could be exerting their influence on hippocampal neurogenesis.

One question that we frequently deal with is: Are more new neurons better for behaviour? In our early work we showed that high levels of estradiol are associated with increased cell proliferation at the same time point (4 h after injection) and same dose $(10 \mu \mathrm{g})$ as when we see impaired reference memory performance in the radial arm maze (Galea et al., 2001). This early relationship suggested to us that high levels of cell proliferation may not be conducive to improved function in the hippocampus at least in female rats, as neither reference nor working memory was facilitated in female rats given high estradiol. This relationship of enhanced cell proliferation and poorer reference memory has since been demonstrated in the literature multiple times (see below).

Hormonal control of hippocampus-dependent learning and memory

Adult neurogenesis in the hippocampus and learning

A growing body of literature is beginning to shed light on the functional significance of adult generated neurons in the hippocampus. Although controversial it is widely believed that adult generated neurons contribute to the mnemonic functions of the hippocampus, namely spatial and contextual memory. Gould and colleagues (1999) were the first to provide strong evidence of an interaction between learning and hippocampal neurogenesis. In that study, it was shown that spatial learning or trace eyeblink conditioning, both hippocampus-dependent tasks, occurring after an injection of BrdU were capable of increasing the number of surviving BrdU labeled cells. This finding triggered 
a number of consequent studies, several of which supported an increase in cell survival with hippocampus-dependent learning (Ambrogini et al., 2000; Leuner et al., 2004; Hairston et al., 2005; Olariu, Cleaver, Shore, Brewer \& Cameron, 2005). However there are a number of incongruent findings showing that hippocampus-dependent learning had no effect on cell survival (Dobrossy et al., 2003; Van der Borght, Wallinga, Luiten, Eggen \& Van der Zee, 2005) as well as a few studies showing a decrease in cell survival following hippocampus-dependent learning (Ambrogini et al., 2004; Pham, McEwen, Ledoux \& Nader, 2005; Olariu et al., 2005). Although there were a number of differences in these studies related to the type of hippocampus-dependent learning used and methodological differences related both to behavioural training and cell labeling techniques, the varied findings suggest that the interaction between neurogenesis and hippocampus-dependent learning is complex.

One of the critical factors that must be considered in such studies is the time between BrdU administration and behavioural training. Our laboratory has recently demonstrated that spatial learning can enhance cell survival but only when training occurred 6-10 days (but not 1-5 or 11-15 days) following BrdU administration (Epp et al., 2007). The 6-10 day time point corresponds approximately to the time when immature neurons are extending axons to the CA3 region and are making rudimentary connections with their targets (Hastings \& Gould, 1999; Markakis \& Gage, 1999; Stanfield \& Trice; 1988). Intuitively, increased synaptic activity during these processes could certainly be responsible for altering cell survival through an activity-dependent mechanism. Earlier work from our laboratory has shown that estradiol administered during this time period not only enhances cell survival but also is associated with better spatial memory (Ormerod et al., 2004). We have also collected some preliminary data showing that the amount of time that passes after learning interacts with cell survival (Epp, Haack \& Galea, 2008). When rats were trained 11-15 days after BrdU injection and perfused on day 16 there was no significant effect of spatial learning on cell survival. However, if the rats are 
instead perfused on day 20 there is a decrease in cell survival in those rats that were trained on the spatial task (Epp, et al., 2008).

What does an increase or decrease in adult neurogenesis ultimately mean for hippocampusdependent learning and memory? One method of addressing this is to experimentally increase or decrease neurogenesis to determine the effects on behaviour. Studies that have experimentally eliminated (or greatly reduced) adult neurogenesis found that contextual learning is disrupted but spatial learning in the Morris water task is not disrupted (Saxe et al., 2006; Shors, Townsend, Zhao, Kozorovitskiy \& Gould, 2002). However, there is some evidence that decreasing adult neurogenesis impairs long-term spatial memory without affecting spatial learning (Snyder, Kee, \&Wojtowicz, 2001). Interestingly, depleting neurogenesis impairs a rapidly acquired form of spatial learning (Winocur et al., 2006). Thus, adult neurogenesis may have multiple functions including long-term memory and consolidation of rapidly acquired information. Studies that have used irradiation or pharmacological blockade of proliferation (i.e. methylazoxymethanol acetate) to experimentally reduce or eliminate adult neurogenesis as a tool to explore the function of adult neurogenesis are not without controversy (Leuner, Gould \& Shors, 2006): 1) neither treatment completely eliminates adult neurogenesis in the hippocampus; 2) neither focal irradiation nor anti-mitotic agents specifically target progenitor cells; and 3) irradiation also upregulates microglia (Hagberg \& Mallard, 2005), which itself suppresses neurogenesis and learning and memory (Hagberg \& Mallard, 2005). Thus we have sought to explore the relationship between neurogenesis and learning and memory with and without the effects of steroid hormones prior to using elimination strategies. It is important to know what relationship exists between neurogenesis and learning under 'natural' conditions to complement studies using elimination techniques. 
While it is clear that there is a relationship between neurogenesis and at least some forms of hippocampus-dependent learning, it does not appear that having a greater number of new neurons is universally better. Although there are numerous examples of positive correlations between adult neurogenesis and learning or memory (Nilsson, Perfilieva, Johansson, Orwar \& Eriksson, 1999; van Praag, Christie, Sejnowski \& Gage, 1999), there are also examples wherein high rates of adult neurogenesis are associated with poor hippocampus-dependent behaviour (Jessberger, Romer, Babu \& Kempermann, 2005). Seizure activity is known to increase adult neurogenesis (Jessberger et al., 2005) and is also associated with impaired performance on hippocampus-dependent tasks (Lopes da Silva, Gorter \& Wadman, 1986). A recent study demonstrated that the impaired performance on an object recognition task following kainic acid induced status epilepticus arises as a result of the increase in neurogenesis (Jessberger et al., 2007). Furthermore, Jin and colleagues found evidence that neurogenesis is enhanced in Alzheimer's disease and hippocampus-dependent memory is impaired (Jin, Galvan, et al., 2004; Jin, Peel, et al., 2004). Although enhanced neurogenesis is clearly not the primary pathology associated with Alzheimer's disease it may exacerbate the cognitive deficits. Young neurons are highly excitable (Schmidt-Heiber, Jonas \& Bischofberger, 2004; Snyder, Kee, \&Wojtowicz, 2001) and as such they may increase the baseline level of excitation in the hippocampus making it more difficult to detect a true excitatory signal, a suggested mechanism involved in the cognitive decline in Alzheimer's disease (Parsons, Stoffler \& Danysz, 2007). Although the majority of evidence suggesting that high levels of neurogenesis are associated with poor learning and memory are based on pathological conditions, we have found evidence in our laboratory that cell survival is enhanced by spatial learning but only in poor learners and not in good learners (Epp et al., 2007). Our finding is in agreement with that of Dobrossy et al. (2003) who showed that low levels of cell survival were predictive of better performance on a spatial learning task. Thus, it must be considered that high levels of neurogenesis are not simply disruptive in pathological circumstances but possibly in the intact brain 
as well. Furthermore, because eliminating neurogenesis also has negative consequences for learning and memory it is likely that there is an optimal level of neurogenesis above or below which learning and memory may be impaired. Consistent with this idea a recent computer model illustrated this same point, that very high levels of cell proliferation will destabilize neuronal activity in the hippocampus causing interference to the proper function of the dentate gyrus (Butz, Lehmann, Dammasch, \& Teuchert-Noodt, 2006).

\section{Cognition and estrogens}

We aim to understand how estradiol influences learning and memory processes and to determine the sites of action of estrogen on learning and memory in the brain. Early work during my graduate studies found that spatial learning in the female rodent was related to both adult and developing levels of gonadal hormones (Galea, Kavaliers \& Ossenkopp, 1994; Galea, Kavaliers, Ossenkopp \& Hampson, 1995). Endogenously high levels of estrogen are negatively correlated with spatial performance in the adult female meadow vole and laboratory rat (for review see Galea et al., 1996; Galea et al., 2000). Evidence suggests that different brain regions are responsible for different types of memory, two of which are working and reference memory. Working memory can be defined as manipulation and retrieval of trial-unique information to guide prospective action and is disrupted by inactivation of the hippocampus and prefrontal cortex (Baddeley, 2003; Yoon, Okada, Jung, \& Kim, 2008). Reference memory can be defined as a long-term stable memory and is disrupted by lesions to the hippocampus and the caudate nucleus (White \& McDonald, 2002). In order to study the effects of hormones on learning and memory, we utilise a number of different tasks that vary in working and/or reference memory load and the neural regions that mediate performance on these tasks. Past literature describing the effects of estradiol on learning and memory is equivocal. This is likely due to the fact that different studies investigating the effects of estradiol on cognition have used: 1) different mazes, in 
which performance relies on the integrity of different brain regions, 2) different doses of estradiol, and 3) different time of exposure to hormone and testing on the maze which may lead to differences in genomic and non-genomic influences of estradiol on cognition. Findings from my laboratory have recently shown that all of these factors can influence estradiol's effects on learning and memory (Galea et al., 2001; Holmes, Wide \& Galea, 2002; Sinopoli, Floresco \& Galea, 2006; Wide et al., 2004). We have systematically investigated the effects of estradiol on learning by: 1) testing the effect of a high dose of estradiol on different versions of the radial arm maze (Galea et al., 2001), 2) varying the dose of estradiol given in the spatial working/reference memory task (Holmes et al., 2002), delayed nonspatial alternation task (Wide, Hanratty, Ting, Galea, 2004), and delayed win shift (Sinopoli et al., 2006); and 3) infusing estradiol directly into prefrontal cortex or hippocampus to investigate its effects on working memory (Sinopoli et al., 2006). In these studies, we found that a very high systemic dose of estradiol impaired performance in the hippocampus-dependent spatial working/reference memory radial arm maze, caudate-dependent cued win-stay, and the amygdala-dependent conditioned place preference, but had no significant effects on the hippocampus and prefrontal cortex-dependent delayed win-shift task (Galea et al., 2001). In addition, we found that high levels of estradiol impair both working and reference memory, while low levels of estradiol facilitate working memory but not reference memory (Galea et al., 2001; Holmes et al., 2002). This suggests a dissociation of the effects of estradiol on working and reference memory processes and that estradiol affects cognition regulated by different brain areas. Intriguingly we have recently found that estradiol infused into either the dorsal hippocampus or prefrontal cortex facilitated working memory in the delayed win-shift but at different doses (Sinopoli et al., 2006). Furthermore, working memory was impaired 24 hours after infusion of estradiol into the hippocampus but not the prefrontal cortex suggesting that possible genomic effects of estradiol may impair hippocampus-dependent working memory processes. Thus, the simple phrase 
“estrogen enhances learning” is not valid. Instead, our findings suggest a better description would be “estrogen modulates learning depending on dose and brain regions recruited”.

Although we have mainly focused on how estradiol affects learning in hippocampus-dependent tasks, we have begun to explore the effects of estradiol on tasks that rely on the integrity of other brain regions such as the amygdala, prefrontal cortex and more recently the nucleus accumbens. Earlier work indicated that conditioned place preference, which relies on the integrity of the amygdala and not the hippocampus, was impaired by high doses of estradiol, a relationship that we continue to see with some recent work on conditioned fear (Barha, Martin \& Galea, 2008). We have recently begun to investigate the effects of estrogen on effort-based learning tasks and behavioral flexibility that are dependent on the integrity of dopaminergic transmission in the amygdala, prefrontal cortex, and nucleus accumbens (Floresco \& Ghods-Sharifi, 2007; Floresco, Tse, \& Ghods-Sharifi, 2008). Estradiol is known to modulate dopamine activity (Becker, 1999; Becker \& Hu, 2008) via receptors residing in these brain regions (Shima, Yamaguchi, \& Yuri, 2003; Simerly, Chang, Muramatsu, \& Swanson, 2006) suggesting that decision-making may be influenced by gonadal hormones. Our early results show that estradiol does indeed modulate effort-based decision making in female rats. In effort-based decision making, animals can choose to work more for a larger sugar reward, or exert less effort for a smaller reward. Using an operant chamber, rats could either press a lever once to receive 2 pellets (i.e. low reward lever), or emit an increasing number of presses throughout the testing session (2, 5, 10, or 20 presses) on the high-reward lever for a large reward of 4 pellets. Ovariectomized females chose to exert significantly more effort for a greater reward than those receiving a sham surgery. Interestingly, when estradiol was administered to ovariectomized rats, they chose to exert significantly less effort for a smaller reward compared to baseline responding. Administration of either the ER $\alpha$-selective ligand propyl pyrazole triol or the ERß agonist diarylpropionitrile alone significantly increased subjects’ 
choice to exert more effort for a larger reward. Intriguingly, all of these effects of exogenous estradiol administration were observed 28 hours, but not 4 hours, following the injection, suggesting that estradiol may work through a genomic action to modulate cost/benefit decision making (Uban, Rummel, Chun, Ghods-Sharrif, Floresco, \& Galea, 2008). Further, estradiol may exert effects through actions on the dopaminergic system, as dopamine is the central neurotransmitter mediating effort-based decision making. There are regional differences in the distribution of $\operatorname{ER} \beta$ and ER $\alpha$ within the nucleus accumbens, PFC and amygdala, which should be explored in order to illuminate region-specific effects of estradiol on cost/benefit decision making.

Effects of reproductive experience and depression on brain and behaviour in the mother.

Pregnancy and the postpartum are associated with dramatic fluctuations in steroid and peptide hormones. These hormones play a role in the induction of maternal behaviours and attachment in rodents and humans. Perhaps paradoxically, these same hormonal changes may also contribute to 'baby brain', or memory problems experienced during late pregnancy and the early postpartum, and to the incidence of 'baby blues' or postpartum depression. The nature of the hormonal profile during pregnancy and postpartum results in two distinct patterns of hormones that have been implicated in promoting depression in vulnerable populations: estrogen withdrawal and prolonged exposure to glucocorticoids. Our laboratory studies the effects of reproductive experience on cognition, neuroplasticity and depressive-like behaviours. In this section we will focus on how reproductive experience influences cognition and neuroplasticity in the hippocampus of the mother and on the findings from two animal models of postpartum depression created recently in our laboratory.

Reproductive experience influences structure and function of the hippocampus 
Work in our laboratory, has shown that both structure and function of the hippocampus are influenced by reproductive experience (Pawluski \& Galea, 2006; Pawluski, Vanderbyl, Ragan, \& Galea, 2006a; Pawluski, Walker \& Galea 2006b; Pawluski, Charlier, Lieblich, Hammond, \& Galea, in press). It is well documented that pregnancy and motherhood have marked effects on the physiology and biology of the mother. However, only recently has emphasis been put on how pregnancy and motherhood affect the hippocampal structure and function in the mother. Some of the first work demonstrating that the hippocampus is involved in maternal behavior and motherhood demonstrated that lesions to the hippocampal formation or pathways projecting into the hippocampus altered pup retrieval and nest building (Kimble, Rogers, \& Hendrickson, 1967; Terlecki \& Sainsbury, 1978).

It was not until the late 1990's that the effects of motherhood on hippocampal function and plasticity were further explored. These studies were partially instigated by the popularization of ‘maternal amnesia’ or ‘baby brain’ (Buckwalter et al., 1999; de Groot, Vuurman, Hornstra, \& Jolles, 2006; Galea et al., 2000; Keenan, Yaldoo, Stress, Fuerst, \& Ginsburg, 1998). For example, 75\% of women report short-term memory loss, forgetfulness, disorientation, confusion, lack of concentration, or reading difficulties during late pregnancy and the early postpartum period (Crawley, Dennison, \& Carter, 2003; Parsons \& Redman, 1991). Using rodent models, we, along with others, have investigated how pregnancy (Galea et al, 2000) and motherhood (Kinsley et al, 1999; Pawluski et al., 2006 a,b) affect spatial cognition in the mother. Work from our laboratory and others has demonstrated that, during late pregnancy and the early postpartum, female rats are impaired on a test of spatial ability (Darnaudéry et al., 2007; Galea et al., 2000), similar to what is seen in humans (Buckwalter et al., 1999; Vanston \& Watson, 2005). Conversely, after weaning, motherhood improves spatial working and reference memory (Kinsley et al., 1999; Pawluski et al., 2006 a,b). Further we have produced some of the first research investigating how reproductive experience, defined as the number of times 
pregnant and mothered, affects spatial cognition and hippocampal plasticity in the mother (Pawluski \& Galea, 2006; Pawluski et al, 2006 a,b; Pawluski \& Galea, 2007).

The initial transition to motherhood is significantly different than subsequent maternal experiences in terms of hormone profiles, maternal behaviors, and neural measures (Moltz \& Robbins, 1965; Svare \& Gandelman, 1976; Bridges \& Hammer 1992; Bridges, Felicio, Pellerin, Stuer, \& Mann, 1993; Featherstone, Fleming, \& Ivy, 2000). Therefore the work from my laboratory investigated not only the initial transition to motherhood, but also how subsequent maternal experiences affect hippocampal plasticity and function. Our work demonstrated that first-time mothers exhibit significant changes in hippocampal morphology (Pawluski \& Galea, 2006), adult neurogenesis within the hippocampus (Pawluski \& Galea, 2007), spatial learning and memory performance (Pawluski et al., 2006a,b), and corticosterone profiles during lactation (Pawluski et al., in press) compared to secondtime mothers or virgin females ( for review, see Pawluski \& Galea, 2008). For example, Pawluski and Galea (2006) demonstrated that primiparous (first-time mother) rats, have decreased dendritic arbourizations in the CA1 and CA3 regions of the hippocampus compared to multiparous (second time mothers) and nulliparous (virgin) female rats at the time of weaning. Further we showed that adult neurogenesis in the hippocampus is suppressed in the early postpartum in primiparous rats compared to nulliparous rats consistent with other studies (Darnaudery et al., 2007; Leuner, Mirescu, Noiman, \& Gould, 2007). In addition we found that multiparous rats have enhanced cell survival compared to primiparous rats in the hippocampus across the postpartum (Pawluski \& Galea, 2007). Furthermore, we found that after weaning, primiparous, and to a lessor extent multiparous, rats have enhanced spatial working memory compared to nulliparous rats (Pawluski et al., 2006 a,b). These data have interesting implications for the effects of pregnancy and motherhood on the human brain and behavior, suggesting that the initial transition to motherhood is significantly different from subsequent maternal experiences. 
This is perhaps not surprising, as the first time mother needs to effectively acquire a suite of maternal behaviors necessary to ensure offspring survival and achieve reproductive success.

\section{Animal models of postpartum depression}

Depression affects approximately 1 in 5 people worldwide (Gutiérrez-Lobos et al., 2002). The incidence of depression is 2-3 times higher in women, particularly over the reproductive years and depression is the leading psychiatric disease among women (Gutiérrez-Lobos et al., 2002).

Furthermore, there are sex differences in the effects of antidepressants used to treat depression (Kornstein, Sloan, \& Thase, 2002). Curiously, most animal models of depression have utilised only male subjects (Jaako-Movits \& Zharkovsky, 2005) and, given the sex differences in incidence of depression and treatment, it is vitally important to validate animal models of depression using female subjects.

The postpartum period is considered the time of greatest risk to develop major depression in women (Drevets \& Todd, 2005). Postpartum depression (PPD) affects approximately 15\% of women and women with untreated PPD have impaired cognitive ability, increased marital difficulties, and are more likely to commit infanticide and abuse their children (Goodman, 2007). In addition to the devastating effects of this disorder on the mother, children of depressed mothers are affected by this early adverse environment. In fact, children of mothers with PPD have an increased risk to develop depression and present with impaired cognitive, motor and social development (Deave, Heron, Evans, \& Emond, 2008; Nomura, Wickramaratne, Warner, Mufson, \& Weissman, 2002). During pregnancy and postpartum, levels of steroid and peptide hormones fluctuate dramatically and these fluctuations may contribute to the etiology of postpartum depression (Hendrick et al., 1998). Profound changes in hormone levels, such as estradiol, corticosterone, corticotropic releasing hormone (CRH) and oxytocin, 
occur in both the rodent and human albeit with different profiles and gestational periods. We have created two animal models of PPD based on two key hormones, estrogen and corticosterone, that may contribute to depression (Brummelte, Pawluski \& Galea, 2006; Galea et al., 2001). Estrogen levels are sustained at elevated levels throughout the third trimester but drop dramatically after parturition, leading to the hypothesis that an "estrogen-withdrawal state" during the first few weeks after parturition contributes to PPD (Hendrick et al., 1998). In fact, increased incidence and severity of depression is reported during menstruation and perimenopause, which are associated with a decline in ovarian hormones (Kornstein, 2002; Schmidt \& Rubinow, 2006). PPD and perimenopausal depressive symptoms are attenuated by estradiol treatment in women (Gregoire, Kumar, Everitt, Henderson, \& Studd, 1996; Schmidt \& Rubinow, 2006). These findings suggest that low or declining estradiol levels may predispose vulnerable women to depression. Indeed, it may be that vulnerable women respond differently to declining hormones than non-vulnerable women. For example, in an elegant study by Bloch et al. (2000) women with a previous history of PPD showed greater mood alterations in response to estradiol withdrawal than women without a previous history of PPD. This research illustrates that women with a predisposition to depression may be more sensitive to large fluctuations in steroid hormone levels. Along with fluctuations in ovarian steroids, another steroid hormone, cortisol, has been implicated in depression. Stress is cited as the leading cause of depression by depressed patients (Bale, 2006; Miller, Chen, \& Zhou, 2007; Schüle, 2007). Depressed patients, including those with PPD, show abnormal hypothalamic-pituitary-adrenal (HPA) function such as hypersecretion of cortisol (Lommatzsch et al., 2006; Miller et al., 2007; Schüle, 2007). Furthermore, PPD patients exhibit blunted adrenalcorticotropic hormone (ACTH) responses (Magiakou et al., 1996) and do not exhibit the normal association between ACTH and cortisol (Jolley, Elmore, Barnard, \& Carr, 2007). In fact, a dysregulation of the HPA system is the most prominent endocrine change in depression and normalizing the HPA axis is one of the major targets of recent therapies (Schüle, 2007). The 
postpartum is, therefore, a unique time in a woman’s life, due to fluctuating ovarian hormones, heightened adrenal steroids and altered HPA function, which could render susceptible women more vulnerable to depression.

Based on the premise that estradiol withdrawal may precipitate PPD in vulnerable women, we created an animal model of PPD focused on estradiol withdrawal (Galea et al., 2001; Green \& Galea, 2008). In this model, female rats exhibit depressive-like symptomology (increased immobility in the forced swim test) that was alleviated by postpartum treatment with estradiol (Galea et al., 2001; Stoeffel \& Craft, 2004). Recently we found that adult hippocampal neurogenesis was suppressed in rats given the estrogen-withdrawal 'PPD' which was rescued by the antidepressant, imipramine (Green \& Galea, 2008). Curiously, in this study imipramine significantly increased hippocampal neurogenesis in intact females but not in ovariectomized rats (see Figure 2). Furthermore, another study found that chronic fluoxetine increased cell proliferation in both male and female intact mice but the effect size was larger in males than in females (Lagace, Fischer, \& Eisch, 2007). These findings suggest that the ability of antidepressants to promote hippocampal neurogenesis in the adult female rat may be affected by ovarian hormone status.

Lisa Kalynchuk and colleagues developed an animal model of depression by administering high levels of corticosterone (CORT; the main glucocorticoid in rats) for 21 days (Kalynchuk, Gregus, Boudreau, \& Perrot-Sinal, 2004). After chronic treatment with CORT, both male and female rats exhibited depressive-like behaviours in the forced swim test. Cortisol levels in humans are maintained at high levels throughout pregnancy and postpartum which could contribute to PPD in susceptible individuals (Bloch et al., 2005; Magiakou et al., 1996). Recent evidence from our laboratory shows that corticosterone binding globulin (CBG) levels are low throughout the postpartum and because CBG binds with CORT this suggests that free CORT levels are higher during postpartum compared to 
control rats (Pawluski et al., in press). Thus it is possible that vulnerable women may be affected negatively by exposure to prolonged high cortisol levels. In fact, women, who previously suffered from PPD, report more depressive symptoms and show greater cortisol responses after exposure to a hormone simulated pregnancy (Bloch et al., 2005), suggesting that in vulnerable women, the HPA axis and mood are altered in response to pregnancy hormones. Recently we created another model of PPD and/or postpartum stress by administering high levels of CORT during the postpartum (Brummelte et al., 2006). The unique feature of this model is that it allows us to study both the mother and the offspring, in order to investigate the effects of PPD not only in dams but also the subsequent consequences on the development of the offspring. We found that dams given high CORT postpartum exhibited 'depressive-like' behaviours in the forced swim test (increased immobility and decreased struggling) as well as alterations in their maternal care (less time on the nest but no significant differences in licking). These findings are consistent with the human literature showing that depressed mothers display less mother-infant interaction (Herrera, Reissland, \& Shepherd, 2004; RighettiVetema, Conne-Perréard, Bousquet, \& Manzano, 2002). In terms of how CORT treatment to the dams affected the offspring, we found that during adolescence male offspring of CORT-treated dams exhibited a decrease in cell proliferation in the dentate gyrus of the hippocampus, which is particularly interesting as decreased hippocampal cell proliferation in adulthood has been linked to depression (Chen, Pandey, \& Dwivedi, 2006; Green \& Galea, 2008; Jaako-Movits, \& Zharkovsky, 2005). Although as adults the offspring of the CORT-treated dams showed no 'depressive-like' behaviour in the forced swim test, they showed increased anxiety-like behaviours and 'impulsivity', which were more pronounced in male than in female offspring (Brummelte et al., 2006). These findings partially parallel the human literature in which boys of PPD mothers are more likely to show depressive symptoms, antisocial behaviour, and hyperactivity (Hay, Pawlby, Angold, Harold, \& Sharp, 2003; Weissman, Warner, Wickramaratne, Moreau, \& Olfson, 1997). These findings point to the fact that the 
mother's hormonal state, independent of amount of maternal licking, can influence emotional and neural outcomes in her offspring and potentially influence their vulnerability to subsequent neuropsychiatric disorders later in life. Further, this model will allow us to study the effects of antidepressants on the maternal depressive state and also their impact on the offspring's brain development. Preliminary data from our laboratory and other studies (Wartella et al., 2003) suggests that postpartum females are less sensitive to stress and high levels of corticosterone compared to virgins or males, thus it is conceivable that antidepressants might have a divergent effect on neuronal and behavioural measures of depression in the postpartum female compared to males or nonreproductive females.

\section{Conclusions}

Our laboratory studies the influence of steroid hormones on brain and behaviour. We have found that estrogens rapidly influence cell proliferation and neurogenesis in the hippocampus of rodents. These estradiol-mediated changes in neurogenesis may be contributing to estradiol-mediated changes in cognition, and experiments in our laboratory are beginning to address this question. Further research has found that androgens, independent of estradiol, upregulate neurogenesis by enhancing cell survival in the dentate gyrus of adult male rats. We have also found that estradiol influences cognition in female rats, with high doses impairing reference and working memory and low doses enhancing working memory. Estradiol appears to enhance working memory through its actions on both the prefrontal cortex and hippocampus. We also demonstrated that reproductive experience, which is accompanied by marked changes in steroid hormones, significantly influences hippocampal plasticity and cognition in the female rat, with primiparous rats exhibiting the most dramatic changes in spatial memory and hippocampal morphology. 
It is important to remember that any theoretical or empirical model of any disorder should consider how well the model works using both the male and female, especially when sex differences are seen in a particular disorder of interest such as in depression. In our own work we have found that while acute stress, exposure to predator odour, increases CORT and suppresses cell proliferation in adult male, the same relationship is not seen in females (Falconer \& Galea, 2003). Furthermore chronic restraint stress results in dendritic atrophy in different areas of the CA3 region of the hippocampus in both male and female rats (Galea et al., 1997) which is coincident with impaired spatial working memory in male rats but paradoxically enhanced spatial working memory in female rats (Bowman, Zrull, \& Luine, 2001; Luine, 2002). These studies and others demonstrate that the female brain is organized differently and responds to ovarian and adrenal steroids in a different way than the male brain. It is of the upmost importance to investigate the effects on neuroplasticity and behaviour in both the male and the female, particularly when modelling diseases that exhibit sex differences in the incidence, etiology or treatment. Further to better understand endocrine regulation of cognition and neuroplasticity one has to keep the complex interactions between sex, hormone type, dose, exposure time and affected brain structure in mind. These complex interactions are what drive the field of behavioural neuroendocrinology into exciting new directions. 


\section{Acknowledgements}

We thank Stephanie Lieblich for her wonderful technical assistance and comments on this review. We also thank past laboratory members for their work and consul, especially, Jennifer Barker, Tamara Crozier, Erin Falconer, Dr. Melissa Holmes, Dr. Brandi Ormerod, Dr. Mark Spritzer, Steven Wainwright and Dr. Jennifer Wide. LAMG is funded by CIHR, NSERC and Pacific Alzheimer Research Foundation (PARF). Funding for graduate students is provided by Integrated Mentor Program in Addictions Research Training (KU), Michael Smith Senior Graduate Studentship (JRE), NSERC PGS-D (CKB), Arthur \& June Willms Fellowship (WLW) Canadian Post-Doctoral Research Fellowship (SB), and NSERC PDF (JLP). 


\section{References}

Ambrogini, P., Cuppini, R., Cuppini, C., Ciaroni, S., Cecchini, T., Ferri, P., et al. (2000). Spatial learning affects immature granule cell survival in adult rat dentate gyrus. Neuroscience Letters, 286(1), 21-24.

Ambrogini, P., Orsini, L., Mancini, C., Ferri, P., Ciaroni, S., \& Cuppini, R. (2004). Learning may reduce neurogenesis in adult rat dentate gyrus. Neuroscience Letters, 359(1-2), 13-16.

Baddeley A. (2003). Working memory: looking back and looking forward. Nature Reviews Neuroscience, 4(10), 829-839.

Bale T.L. (2006). Stress sensitivity and the development of affective disorders. Hormones and Behavior, 50(4), 529-533.

Barha C.K., Barker J.M., Brummelte S., Epp, J.R., \& Galea, L.A.M., (in press June 16, 2008). Gonadal and adrenal hormone regulation of adult neurogenesis. In. D. Pfaff (Ed.). Hormones, Brain and Behavior (2 ${ }^{\text {nd }}$ Ed.) (pp. xxx). San Diego: Academic Press/Elsevier.

Barha, C.K., Lieblich, S.E., \& Galea, L.A.M. (submitted) Different forms of oestrogen rapidly upregulate hippocampal neurogenesis in the dentate gyrus of young female rats. Journal of Neuroendocrinology.

Barha C. K., Martin M. B., \& Galea L.A.M. (2008). Differential effects of 17 $\alpha$-estradiol, 17 $\beta$-estradiol, and estrone on contextual and cued fear conditioning in young adult female rats. Society for Behavioral Neuroendocrinology Abstracts. 
Barker, J.M., \& Galea, L.A. (2008). Repeated estradiol administration alters different aspects of neurogenesis and cell death in the hippocampus of female, but not male, rats. Neuroscience, 152, 888-902.

Becker J.B. (1999). Gender Differences in Dopaminergic Function in Striatum and Nucleus Accumbens. Pharmacology, Biochemistry and Behavior, 64(4), 803-812.

Becker J.B., \& Hu M. (2008). Sex Differences in Drug Abuse. Frontiers in Neuroendocrinology, 29(1), 36-47.

Bloch M., Schmidt P.J., Danaceau M., Murphy J., Nieman L., \& Rubinow D.R. (2000). Effects of gonadal steroids in women with a history of postpartum depression. American Journal of Psychiatry, 157(6), 924-930.

Bloch M., Rubinow D.R., Schmidt P.J., Lotsikas A., Chrousos G.P., Cizza G. (2005). Cortisol response to ovine corticotropin-releasing hormone in a model of pregnancy and parturition in euthymic women with and without a history of postpartum depression. Journal of Clinical Endocrinology \& Metabolism, 90(2), 695-699.

Bowman R.E., Zrull M.C., \& Luine V.N. (2001). Chronic restraint stress enhances radial arm maze performance in female rats. Brain Research, 904, 279-289.

Bridges R.S., Felicio L.F., Pellerin L.J., Stuer A.M., \& Mann P.E. (1993). Prior parity reduces postcoital diurnal and nocturnal prolactin surges in rats. Life Science, 53, 439-445.

Bridges R.S., \& Hammer R.P. (1992). Parity-associated alterations of medial preoptic opiate receptors in female rats. Brain Research, 578, 269-274. 
Brown J.P., Couillard-Despres S., Cooper-Kuhn C.M., Winkler J., Aigner L., \& Kuhn H.G. (2003).

Transient expression of doublecortin during adult neurogenesis. Journal of Comparative Neurology, 467, 1-10.

Brummelte, S., Pawluski, J.L. \& Galea, L.A.M. (2006).High postpartum levels of corticosterone given to dams influence postnatal neurogenesis and behaviour of offspring: A model of post-partum stress and possible depression. Hormones and Behavior, 50, 370-382.

Buckwalter J.G., Stanczyk F.Z., McCleary C.A., Bluestein B.W., Buckwalter D.K., Rankin K.P., Chang L., \& Goodwin T.M. (1999). Pregnancy, the postpartum, and steroid hormones: effects on cognition and mood. Psychoneuroendocrinology, 24, 69-84.

Butz M., Lehmann K., Dammasch I.E., \& Teuchert-Noodt G. (2006). A theoretical network model to analyse neurogenesis and synaptogenesis in the dentate gyrus. Neural Networks, 19(10), 14901505.

Cameron H.A., \& McKay R.D. (2001). Adult neurogenesis produces a large pool of new granule cells in the dentate gyrus. Journal of Comparative Neurology, 435(4), 406-417.

Cameron H.A., Woolley C.S., McEwen B.S., \& Gould E. (1993). Differentiation of newly born neurons and glia in the dentate gyrus of the adult rat. Neuroscience, 56(2), 337-344.

Chen H., Pandey G.N., \& Dwivedi Y. (2006). Hippocampal cell proliferation regulation by repeated stress and antidepressants. Neuroreport, 17(9), 863-867.

Crawley R.A., Dennison K., \& Carter C. (2003). Cognition in pregnancy and the first year post-partum. Psychology and Psychotherapy, 76, 69-84. 
Daniel J.M., Winstauer P.J., \& Moerschbaecher J.M. 2003. Castrtion in rats impairs performance during acquisition of a working memory task and exacerbates deficits in working memory produced by scopolamine and mecamylamine. Psychopharmocology, 170, 294-300.

Darnaudéry M., Perez-Martin M., Del Favero F., Gomez-Roldan C., Garcia-Segura L.M., \& Maccari S. (2007). Early motherhood in rats is associated with a modification of hippocampal function. Psychoneuroendocrinology, 32, 803-812

Deave T., Heron J., Evans J., \& Emond A. (2008), The impact of maternal depression in pregnancy on early child development. BJOG, 115(8), 1043-1051.

de Groot R.H., Vuurman E.F., Hornstra G., \& Jolles J. (2006). Differences in cognitive performance during pregnancy and early motherhood. Psychological Medicine, 36, 1023-1032.

Drevets, W.C. \& Todd, R.D. (2005). Depression, mania and related disorders. In E. Rubin \& C. Zorumski (Eds). Adult psychiatry (2 ${ }^{\text {nd }}$ ed). (pp. 91-129). Oxford: Blackwell Publishing.

Dobrossy, M. D., Drapeau, E., Aurousseau, C., Le Moal, M., Piazza, P. V., \& Abrous, D. N. (2003). Differential effects of learning on neurogenesis: learning increases or decreases the number of newly born cells depending on their birth date. Molecular Psychiatry, 8(12), 974-982.

Edinger, K.L.\& Frye, C.A. (2007). Androgens’ performance-enhancing effects in the inhibitory avoidance and water maze tasks may involve actions at intracellular androgen receptors in the dorsal hippocampus. Neurobiology of Learning and Memory 87, 201-208.

Epp, J.R., Haack, A.K. \& Galea, L.A.M. (2008). Hippocampus-dependent learning increases and decreases survival of new cells in the dentate-gyrus at specific times during cell maturation. Society for Neuroscience Abstracts. 
Epp, J. R., Spritzer, M. D., \& Galea, L. A. M. (2007). Hippocampus-dependent learning promotes survival of new neurons in the dentate gyrus at a specific time during cell maturation. Neuroscience, 149(2), 273-285.

Falconer, E.M. \& Galea, L.A.M. (2003). Sex differences in defensive behaviors, cell proliferation and survival in the dentate gyrus in response to acute predator odor stress. Brain Research, 975, 2236.

Featherstone, R. E., Fleming A. S., \& Ivy, G. O. (2000). Plasticity in the maternal circuit: effects of experience and partum condition on brain astrocyte number in female rats. Behavioral Neuroscience, $114,158-172$.

Floresco S.B., \& Ghods-Sharifi, S. (2007). Amygdala-prefrontal cortical circuitry regulates effortbased decision making. Cerebral Cortex, 17(2), 251-260.

Floresco S. B., Tse, M.T.L., \& Ghods-Sharifi, S. (2008). Dopaminergic and Glutamatergic Regulation of Effort and Delay-Based Decision Making: Neuropsychopharmacology, 33(8), 966-79.

Frye C.A., \& Seliga, A.M. (2001). Testosterone increases analgesia, anxiolysis, and cognitive performance of male rats. Cognitive, Affective \& Behavioral Neuroscience, 1(4), 371-381.

Galea, L.A.M. (2008). Gonadal Hormone Modulation of Neurogenesis in the Dentate Gyrus of Adult Male and Female Rodents. Brain Research Reviews, 57, 332-341.

Galea, L.A.M., Kavaliers, M., \& Ossenkopp, K.-P. (1994). Performance (re-acquisition) of a watermaze task by adult meadow voles: Effects of age of juvenile acquisition and in utero environment (litter sex-ratio). Behavioral Brain Research, 63, 177-185. 
Galea, L.A.M., Kavaliers, M., Ossenkopp, K.-P., \& Hampson, E. (1995). Gonadal hormones and spatial learning in the Morris water-maze in the male and female meadow vole, Microtus pennsylanicus. Hormones and Behavior, 29, 106-125.

Galea, L.A.M., Kavaliers, M., \& Ossenkopp, K.-P. (1996). Sexually-Dimorphic Spatial Learning in Meadow Voles, Microtus pennsylvanicus and Deer Mice, Peromyscus maniculatus. Journal of Experimental Biology, 199, 195-200.

Galea L.A.M., \& McEwen B. S. (1999). Sex and seasonal differences in the rate of cell proliferation in the dentate gyrus of adult wild meadow voles. Microtus Pennsylvannicus. Neuroscience, 89, 955-964.

Galea L.A.M., McEwen B.S., Tanapat P., Deak T., Spencer R.L., \& Dhabar F.S. (1997). Sex differences in dendritic atrophy of CA3 pyramidal neurons in response to chronic restraint stress. Neuroscience, 81, 689-697.

Galea L.A.M., Ormerod B.K., Sampath S., Kostaras X., Wilkie D.M., \& Phelps M.T. (2000). Spatial working memory and hippocampal size across pregnancy in rats. Hormones and Behavior, 37, 86-95.

Galea, L.A.M., Perrot-Sinal, T. S., Kavaliers, M., Ossenkopp, K.P. (1999). Relationships of hippocampal volume and dentate gyrus width to gonadal hormone levels in male and female meadow voles. Brain Research, 821, 383-391.

Galea, L.A.M., Wide, J. K., Paine, T. A., Holmes, M. M., Ormerod, B. K., \& Floresco, S. B. (2001). High levels of estradiol disrupt conditioned place preference learning, stimulus response learning 
and reference memory but have limited effects on working memory. Behavioural Brain Research, 126, 115-126.

Goodman, S.H. (2007). Depression in mothers. Annual Review of Clinical Psychology, 3, 107-135.

Gould E. (2007). How widespread is adult neurogenesis in mammals? Nature Reviews Neuroscience, 8(6), 481-488.

Gould, E., Beylin, A., Tanapat, P., Reeves, A., \& Shors, T. J. (1999). Learning enhances adult neurogenesis in the hippocampal formation. Nature Neuroscience, 2(3), 260-265.

Gregoire, A. J., Kumar, R., Everitt, B., Henderson, A. F., \& Studd, J. W. (1996). Transdermal oestrogen for treatment of severe postnatal depression. Lancet 347, 930-933.

Gutiérrez-Lobos, K., Scherer, M., Anderer, P., \& Katschnig, H. (2002). The influence of age on the female/male ratio of treated incidence rates in depression. BMC Psychiatry, 2, 3, doi:10.1186/1471-244X-2-3.

Hagberg, H., Mallard, C. (2005) Effect of inflammation on central nervous system development and vulnerability. Current Opinions in Neurology, 18: 117-23.

Hairston, I. S., Little, M. T., Scanlon, M. D., Barakat, M. T., Palmer, T. D., Sapolsky, R. M., et al. (2005). Sleep restriction suppresses neurogenesis induced by hippocampus-dependent learning. Journal of Neurophysiology, 94(6), 4224-4233.

Hastings, N. B. \& E. Gould (1999). Rapid extension of axons into the CA3 region by adult-generated granule cells. Journal of Comparative Neurology, 413(1): 146-54. 
Hay D.F., Pawlby S., Angold A., Harold G.T., \& Sharp D. (2003). Pathways to Violence in the Children of Mothers who were depressed postpartum. Developmental Psychology, 39(6), 10831094.

Hendrick, V., Altshuler, L. L., \& Suri, R. (1998). Hormonal changes in the postpartum and implications for postpartum depression. Psychosomatics 39, 93-101.

Herrera E., Reissland N., \& Shepherd J. (2004). Maternal touch and maternal child-directed speech: effects of depressed mood in the postnatal period. Journal of Affective Disorders, 81(1), 29-39.

Herrick, S.P., Waters, E.M., Drake, C.T., McEwen, B.S., \& Milner, T.A. (2006). Extranuclear estrogen receptor beta immunoreactivity is on doublecortin-containing cells in the adult and neonatal rat dentate gyrus. Brain Research, 1121, 46-58.

Holmes, M.M., Wide, J.K. \& Galea, L.A.M. (2002). Low levels of estradiol facilitate while high levels of estradiol impair working memory performance in the working/reference memory version of the radial arm maze. Behavioral Neuroscience, 116, 928-934.

Isgor, C., \& Watson, S.J. (2005). Estrogen receptor alpha and beta mRNA expressions by proliferating and differentiating cells in the adult rat dentate gyrus and subventricular zone. Neuroscience, 134, 847-856.

Jaako-Movits, K., \& Zharkovsky, A. (2005). Impaired fear memory and decreased hippocampal neurogenesis following olfactory bulbectomy in rats. European Journal of Neuroscience 22, 2871-2878.

Janowsky J.S. (2006). The role of androgens in cognition and brain aging in men. Neuroscience, 138, 1015-1020. 
Jessberger, S., Romer, B., Babu, H., \& Kempermann, G. (2005). Seizures induce proliferation and dispersion of doublecortin-positive hippocampal progenitor cells. Experimental Neurology, 196(2), 342-351.

Jessberger, S., Nakashima, K., Clemenson, G. D., Jr., Mejia, E., Mathews, E., Ure, K., et al. (2007). Epigenetic modulation of seizure-induced neurogenesis and cognitive decline. Journal of Neuroscience, 27(22), 5967-5975.

Jin, K., Galvan, V., Xie, L., Mao, X. O., Gorostiza, O. F., Bredesen, D. E., et al. (2004). Enhanced neurogenesis in Alzheimer's disease transgenic (PDGF-APPSw,Ind) mice. Proceedings of the National Academy of Science U S A, 101(36), 13363-13367.

Jin, K., Peel, A. L., Mao, X. O., Xie, L., Cottrell, B. A., Henshall, D. C., et al. (2004). Increased hippocampal neurogenesis in Alzheimer's disease. Proceedings of the National Academy of Science U S A, 101(1), 343-347.

Jolley S.N., Elmore S., Barnard K.E., \& Carr D,B. (2007). Dysregulation of the hypothalamic-pituitaryadrenal axis in postpartum depression. Biological Research for Nursing, 8(3), 210-222.

Kalynchuk, L.E., Gregus, A., Boudreau, D., \& Perrot-Sinal, T.S. (2004). Corticosterone increase depressive-like behaviour, with some effects on predator odor-induced defensive behaviour, in male and female rats. Behavioral Neuroscience, 118(6), 1365-1377.

Kambo, J.S, and Galea, L.A.M. (2006). Activational levels of androgens influence risk assessment behaviour but do not influence stress-induced suppression in hippocampal cell proliferation in adult male rats. Behavioral Brain Research,175, 263-270. 
Kempermann G., Jessberger S., Stiner B., \& Kronenberg G. (2004). Milestones of neuronal development in the adult hippocampus. Trends in Neuroscience, 27, 447-452.

Keenan P.A., Yaldoo D.T., Stress M.E., Fuerst D.R., \& Ginsburg K.A. (1998). Explicit memory in pregnant women. American Journal of Obstetrics and Gynecology, 179, 731-737.

Kimble D.P., Rogers L., \& Hendrickson C.W. (1967). Hippocampal lesions disrupt maternal, not sexual, behavior in the albino rat. Journal Comparative Physiology and Psychology, 63, 401-407.

Kinsley C.H., \& Bridges R.S. (1988). Parity-associated reductions in behavioral sensitivity to opiates. Biology of Reproduction, 39, 270-278.

Kinsley C.H., Madonia L., Gifford G.W., Tureski K., Griffin G.R., Lowry C., Williams J., Collins J., McLearie H., \& Lambert K.G. (1999). Motherhood improves learning and memory. Nature, 402, 137-138.

Koike, S., Sakai, M., \& Muramatsu, M. (1987). Molecular cloning and characterization of rat estrogen receptor cDNA. Nucleic Acids Research 15, 2499-2513.

Kornstein S.G. (2002). Chronic depression in women. Journal of Clinical Psychiatry, 63(7), 602-609.

Kornstein, S.G., Sloan, D.M., \& Thase, M.E. (2002). Gender-specific differences in depression and treatment response. Psychopharmacology Bulletin 36(4), 99-112.

Kritzer M.F., McLaughlin P.J. Smirlis T., \& Robinson J.K. (2001) Gonadectomy impairs T-maze acquisition in adult male rats. Hormones and Behavior 39(2), 167-174. 
Kuiper, G.J.M., Enmark, E., Pelto-Huikko, M., Nilsson, S., \& Gustafsson, J. (1996). Cloning of a novel estrogen receptor expressed in rat prostate and ovary. Proceedings of the National Academy of Science USA, 93, 5925-5930.

Lagace D.C., Fischer S.J., \& Eisch A.J. (2007). Gender and endogenous levels of estradiol do not influence adult hippocampal neurogenesis in mice. Hippocampus 17, 175-180.

Lee, S.J., \& McEwen, B.S. (2001). Neurotrophic and neuroprotective actions of estrogens and their therapeutic implications. Annual Reviews in Pharmacology and Toxicology, 41, 569-591.

Leuner, B., Gould, E., Shors, T.J. (2006). Is there a link between adult neurogenesis and learning?

Hippocampus 16: 216-224.

Leuner, B., S. Mendolia-Loffredo, Y. Kozorovitskiy, D. Samburg, E. Gould \& T. J. Shors (2004). Learning enhances the survival of new neurons beyond the time when the hippocampus is required for memory. Journal of Neuroscience, 24(34), 7477-7481.

Leuner B., Mirescu C., Noiman L., \& Gould E. (2007). Maternal experience inhibits the production of immature neurons in the hippocampus during the postpartum period through elevations in adrenal steroids. Hippocampus, 17, 434-442.

Lommatzsch M., Hornych K., Zingler C., Schuff-Werner P., Höppner J., \& Virchow J.C. (2003). Maternal serum concentrations of BDNF and depression in the perinatal period. Psychoneuroendocrinology, 31(3), 388-394.

Lopes da Silva, F. H., Gorter, J. A., \& Wadman, W. J. (1986). Kindling of the hippocampus induces spatial memory deficits in the rat. Neuroscience Letters, 63(2), 115-120.

Luine V. (2002). Sex differences in chronic stress effects on memory in rats. Stress, 5(3), 205-216. 
Magiakou M.A., Mastorakos G., Rabin D., Dubbert B., Gold P.W., \& Chrousos G.P. (1996)

Hypothalamic corticotropin-releasing hormone suppression during the postpartum period: implications for the increase in psychiatric manifestations at this time. Journal of Clinical Endocrinolgy \& Metabolism, 81(5), 1912-1917.

Malberg J.E., Eisch A.J., Nestler E.J., \& Duman R.S. (2000). Chronic antidepressant treatment increases neurogenesis in adult rat hippocampus. Journal of Neuroscience, 20(24), 9104-9110.

Markakis, E. A., \& Gage, F. H. (1999). Adult-generated neurons in the dentate gyrus send axonal projections to field CA3 and are surrounded by synaptic vesicles. Journal of Comparative Neurology, 406(4), 449-460.

Marcondes F. K., Bianchi F. J., \& Tanno A. P. (2002). Determination of the estrous cycle phases of rats: some helpful considerations. Brazilian Journal of Biology, 62(4A), 609-614.

Mazzucco C.A., Leiblich S.E., Bingham B.I., Williamson M.A., Viau V., \& Galea L.A.M. (2006). Both estrogen receptor $\alpha$ and estrogen receptor $\beta$ agonists enhance cell proliferation in the dentate gyrus of adult female rats. Neuroscience, 141, 1793-1800.

McEwen B.S. (1994). Corticosteroids and hippocampal plasticity. Annals of the New York Academy of Sciences, 746, 134-142.

Miller G.E., Chen E., \& Zhou E.S. (2007). If it goes up, must it come down? Chronic stress and the hypothalamic-pituitary-adrenocortical axis in humans. Psychological Bulletin, 133(1), 25-45.

Mirescu C., \& Gould E. (2006). Stress and adult neurogenesis. Hippocampus, 16, 233-238.

Mohapel, P., Mundt-Petersen, K., Brundin, P., \& Frielingsdorf, H. (2006). Working memory training decreases hippocampal neurogenesis. Neuroscience, 142(3), 609-613. 
Moffat S.D., Zonderman A.B., Metter E.J., Blackman M.R., Hartmean S.M., \& Resnick S.M. (2002) Longitudinal Assessment of serum free testosterone concentration predicts memory performance and cognitive status in elderly men. Journal of Clinical Endocrinology \& Metabolism, 87(11), 5001-5007.

Moltz H., \& Robbins D. (1965). Maternal behavior of primiparous and multiparous rats. Journal Comparative Physiology and Psychology, 60, 417-421.

Nelson, C.J., Lee J.S., Gamboa, M.C. \& Roth, A.J. (2008). Cognitive effects of hormone therapy in men with prostate cancer: a review. Cancer, 113(5), 1097-1106.

Nilsson, M., Perfilieva, E., Johansson, U., Orwar, O., \& Eriksson, P. S. (1999). Enriched environment increases neurogenesis in the adult rat dentate gyrus and improves spatial memory. Journal of Neurobiology, 39(4), 569-578.

Nomura Y., Wickramaratne P.J., Warner V., Mufson L., \& Weissman M.M. (2002). Family discord, parental depression, and psychopathology in offspring: ten-year follow-up. Journal of the American Academy of Child \& Adolescent Psychiatry, 41, 402-409.

Olariu, A., Cleaver, K. M., Shore, L. E., Brewer, M. D., \& Cameron, H. A. (2005). A natural form of learning can increase and decrease the survival of new neurons in the dentate gyrus. Hippocampus, 15(6), 750-762.

Olson A.K., Eadie B.D., Ernst C., \& Christie B.R. (2006). Environmental enrichment and voluntary exercise massively increase neurogenesis in the adult hippocampus via dissociable pathways. Hippocampus, 16(3), 250-260. 
Ormerod, B. K., and Galea, L. A. M. (2003). Reproductive status alters cell survival in the dentate gyrus of adult male rodents. Neuroscience Letters, 346, 25-28.

Ormerod, B. K., Lee, T. T., \& Galea, L. A. M. (2003). Estradiol initially enhances but subsequently suppresses (via adrenal steroids) granule cell proliferation in the dentate gyrus of adult female rats. Journal of Neurobiology, 55, 247-260.

Ormerod, B. K., Lee T.-T. Y. and Galea, L.A.M. (2004). Estradiol enhances neurogenesis in the dentate gyri of adult male meadow voles by increasing the survival of young granule neurons. Neuroscience, 128, 645-654.

Parsons, C. G., Stoffler, A. \& Danysz,W (2007). Memantine: a NMDA receptor antagonist that improves memory by restoration of homeostasis in the glutamatergic system--too little activation is bad, too much is even worse. Neuropharmacology, 53,(6): 699-723.

Parsons C., \& Redman S. (1991). Self-reported cognitive change during pregnancy. Australian Journal of Advanced Nursing, 9, 20-29.

Pawluski J.L., \& Galea L.A. (2006). Hippocampal morphology is differentially affected by reproductive experience in the mother. Journal of Neurobiology, 66, 71-81.

Pawluski, J. L., \& Galea, L. A. (2007). Reproductive experience alters hippocampal neurogenesis during the postpartum period in the dam. Neuroscience, 149(1), 53-67.

Pawluski, J.L. \& Galea, L.A.M. (2008). The Role of Reproductive Experience on Hippocampal function and plasticity. In R.S. Bridges (Ed.) The Neurobiology of the Parental Mind (pp. 493508). San Diego, CA: Elsevier. 
Pawluski J.L., Vanderbyl B.L., Ragan K., \& Galea L.A. (2006a). First reproductive experience persistently affects spatial reference and working memory in the mother and these effects are not due to pregnancy or 'mothering' alone. Behavioural Brain Research, 175, 157-165.

Pawluski J.L., Walker S.K., \& Galea L.A. (2006b). Reproductive experience differentially affects spatial reference and working memory performance in the mother. Hormones and Behavior, 49, 143-149.

Pawluski, J. L., Charlier, T. D., Lieblich, S.E., Hammond G.L., \& Galea, L.A.M. (2008). Reproductive experience alters corticosterone and CBG levels in the rat dam. Physiology and Behavior doi:10.1016/j.physbeh.2008.09.004.

Pham, K., McEwen, B. S., Ledoux, J. E., \& Nader, K. (2005). Fear learning transiently impairs hippocampal cell proliferation. Neuroscience, 130(1), 17-24.

Prickaerts J., Koopmens G., Blokland A., \& Scheepens A. (2004). Learning and adult neurogenesis: survival with or without proliferation? Neurobiology of Learning and Memory, 81, 1-11.

Rannevik, G., Jeppsson, S., Johnell, O., Bjerre, B., Laurell-Borulf, Y., Svanberg, L. (1995). A longitudinal study of the perimenopausal transition: altered profiles of steroid and pituitary hormones, SHBG and bone mineral density. Maturitas, 21, 103-113.

Righetti-Veltema M., Conne-Perréard E., Bousquet A., \& Manzano J. (2002). Postpartum depression and mother-infant relationship at 3 months old. Journal of Affective Disorders, 70(3), 291-306.

Saxe, M. D., Battaglia, F., Wang, J. W., Malleret, G., David, D. J., Monckton, J. E., et al. (2006). Ablation of hippocampal neurogenesis impairs contextual fear conditioning and synaptic 
plasticity in the dentate gyrus. Proceedings of the National Academy of Science U S A, 103(46), 17501-17506.

Schmidt P. J., \& Rubinow D. R. (2006). Reproductive ageing, sex steroids and depression. Journal of the British Menopause Society, 12(4), 178-185.

Schmidt-Hieber, C., Jonas, P., \& Bischofberger, J. (2004). Enhanced synaptic plasticity in newly generated granule cells of the adult hippocampus. Nature, 429(6988), 184-187.

Schüle C. (2007). Neuroendocrinological mechanisms of actions of antidepressant drugs. Journal of Neuroendocrinology, 19(3), 213-226.

Shima N., Yamaguchi Y., \& Yuri K. (2003). Distribution of estrogen receptor mRNA-containing cells in ovariectomized and estrogen-treated female rat brain. Anatomical Science International, 78(2), 85-97.

Shors, T.J. (2004). Learning during stressful times. Learning and Memory, 11, 137-144.

Shors, T. J., Townsend, D. A., Zhao, M., Kozorovitskiy, Y., \& Gould, E. (2002). Neurogenesis may relate to some but not all types of hippocampal-dependent learning. Hippocampus, 12(5), 578584.

Simerly R. B., Chang C., Muramatsu M., \& Swanson L. W. (2006). Distribution of ER Distribution of androgen and estrogen receptor mRNA-containing cells in the rat brain: An in situ hybridization study. Journal of Comparitive Neurology, 294(1), 76-95.

Sinopoli, K.J., Floresco, S.B. and Galea, L.A.M. (2006). Systemic and local administration of estradiol into the prefrontal cortex or hippocampus differentially alters working memory. Neurobiology of Learning and Memory, 86, 293-304. 
Snyder, J. S., Kee, N., \& Wojtowicz, J. M. (2001). Effects of adult neurogenesis on synaptic plasticity in the rat dentate gyrus. Journal of Neurophysiology, 85(6), 2423-2431.

Snyder, J. S., Hong, N. S., McDonald, R. J., \& Wojtowicz, J. M. (2005). A role for adult neurogenesis in spatial long-term memory. Neuroscience, 130(4), 843-852.

Spritzer, M.D., \& Galea, L.A. (2007). Testosterone and dihydrotestosterone, but notestradiol, enhance survival of new hippocampal neurons in adult male rats. Developmental Neurobiology, 67, 13211333.

Spritzer, M.D., Gill, M., Weinberg, A. and Galea, L.A.M. (2008) Castration differentially affects spatial working and reference memory in adult male rats. Archives of Sexual Behavior, 37, 19-29

Stanfield, B. B., \& Trice, J. E. (1988). Evidence that granule cells generated in the dentate gyrus of adult rats extend axonal projections. Experimental Brain Research, 72(2), 399-406.

Stoffel E.C., \& Craft R.M. (2004). Ovarian hormone withdrawal-induced "depression" in female rats. Physiology \& Behavior, 83(3), 505-513.

Stone G.E., Miller O.J., \& Prescott D.M. (1965). $\mathrm{H}^{3}$-thymidine derivative pools in relation to macronuclear DNA synthesis in Tetrahymena pyriformis. Journal of Cellular Biology, 25, 171177.

Svare B., \& Gandelman R. (1976). Postpartum aggression in mice: the influence of suckling stimulation. Hormones and Behavior, 7, 407-416.

Tabori N.E., Stewart L.S., Znamensky V., Romeo R.D., Alves S.E., McEwen B.S., \& Milner T.A. (2005). Ultrastructural evidence that androgen receptors are located at extranuclear sites in the rat hippocampal formation. Neuroscience, 130, 151-163. 
Tanapat P., Hastings N.B., Reeves A.J., \& Gould E. (1999). Estrogen stimulates a transient increase in the number of new neurons in the dentate gyrus of the adult female rat. Journal of Neuroscience, 19(14), 5792-5801.

Taupin P. ( 2007). BrdU immunohistochemistry for studying adult neurogenesis: paradigms, pitfalls, limitations, and validation. Brain Research Reviews, 53, 198-214

Terlecki L.J., \& Sainsbury R.S. (1978). Effects of fimbria lesions on maternal behavior in the rat. Physiology \& Behavior, 21, 89-97.

Thomas R.M., \& Peterson D.A. (2008). Even neural stem cells get the blues: evidence for a molecular link between modulation of adult neurogenesis and depression. Gene Expression, 14(3), 183-193.

Toran-Allerand, C.D., Guan, X., MacLusky, N.J., Horvath, T.L., Diano, S., Singh, M., Connolly, E.S. Jr., Nethrapalli, I.S., Tinnikov, A.A. (2002). ER-X: a novel, plasma membrane-associated, putative estrogen receptor that is regulated during development and after ischemic brain injury. Journal of Neuroscience, 22, 8391-8401.

Uban, K., Rummel, J, Chun M. L., Ghods-Sharrif, S., Floresco, S.B., \& Galea L.A.M. (2008) Estradiol Modulates Effort-Based Decision Making in Rats. Society for Behavioral Neuroendocrinology Abstracts.

Van der Borght, K., Wallinga, A. E., Luiten, P. G., Eggen, B. J., \& Van der Zee, E. A. (2005). Morris water maze learning in two rat strains increases the expression of the polysialylated form of the neural cell adhesion molecule in the dentate gyrus but has no effect on hippocampal neurogenesis. Behavioral Neuroscience, 119(4), 926-932. 
van Praag, H., Christie, B. R., Sejnowski, T. J., \& Gage, F. H. (1999). Running enhances neurogenesis, learning, and long-term potentiation in mice. Proceedings of the National Academy of Science $U$ $S$ A, 96(23), 13427-13431.

van Praag H., Schinder A.F., Christie B.R., Toni N., Palmer T.D., \& Gage F.H.(2002). Functional neurogenesis in the adult hippocampus. Nature, 415(6875), 1030-1034.

Vanston C.M., \& Watson N.V. (2005). Selective and persistent effect of foetal sex on cognition in pregnant women. Neuroreport, 16(7), 779-782.

Wartella J., Amory E., Lomas L.M., Macbeth A., McNamara I., Stevens L., Lambert K.G., Kinsley C.H. (2003). Single or multiple reproductive experiences attenuate neurobehavioral stress and fear responses in the female rat. Physiology \& Behavior, 79(3), 373-381.

Weiland, N.G., Orikasa, C., Hayashi, S., \& McEwen, B.S. (1997). Distribution and hormone regulation of estrogen receptor immunoreactive cells in the hippocampus of male and female rats. Journal of Comparative Neurology, 388, 603-612.

White, N.M. \& McDonald, R.J. (2002). Multiple parallel memory systems in the brain of the rat. Neurobiology of Learning and Memory, 77(2), 125-184.

Wide JK, Hanratty K, Ting J, Galea LAM (2004). High level estradiol impairs and low level estradiol facilitates non-spatial working memory. Behavioral Brain Research, 155, 45-53.

Weissman M.M., Warner V., Wickramaratne P., Moreau D., \& Olfson M. (1997). Offspring of depressed parents. 10 Years later. Archives of General Psychiatry, 54(10), 932-940. 
Winocur, G., Wojtowicz, J. M., Sekeres, M., Snyder, J. S., \& Wang, S. (2006). Inhibition of neurogenesis interferes with hippocampus-dependent memory function. Hippocampus, 16(3), 296-304.

Wolf, O.T. \& Kirschbaum C. (2002). Endogenous estradiol and testosterone levels are associated with cognitive performance in older women and men. Hormones and Behaviour, 41, 259-266.

Woolley C.S., \& McEwen B.S. (1993). Role of estradiol and progesterone in regulation of hippocampal dendritic spine density during the estrous cycle in the rat. Journal of Comparative Neurology, 336(2), 293-306.

Yoon, T., Okada, J., Jung, M.W., \& Kim, J.J. (2008). Prefrontal cortex and hippocampus subserve different components of working memory in rats. Learning and Memory, 15(3), 97-105. 
Table 1. Overview of our current state of knowledge from experiments in our laboratory and others on how androgens and estrogens regulate cell proliferation and survival in the dentate gyrus of adult male and female rodents. RA=reproductively active; RI=reproductively inactive; GDX=gonadectomised; E=estradiol; DHT=dihydrotestosterone, T=testosterone; Sham=gonadally intact; Oil=sesame oil ( vehicle). Empty cells indicate unknown.

\begin{tabular}{|c|c|c|c|c|c|c|c|}
\hline Male & $\begin{array}{c}\text { Cell } \\
\text { proliferation }\end{array}$ & Cell Survival & Species/Paper & Female & $\begin{array}{c}\text { Cell } \\
\text { proliferation }\end{array}$ & $\begin{array}{c}\text { Cell } \\
\text { Survival }\end{array}$ & Species/Paper \\
\hline & $\mathrm{RA}=\mathrm{RI}$ & $\mathrm{RA}>\mathrm{RI}$ & $\begin{array}{l}\text { Voles (Ormerod \& } \\
\text { Galea, 2003) }\end{array}$ & & $\mathrm{RI}>\mathrm{RA}$ & $\mathrm{RA}>\mathrm{RI}^{*}$ & $\begin{array}{c}\text { Voles (Galea \& } \\
\text { McEwen, 1999; } \\
\text { Ormerod \& Galea, } \\
\text { 2001) } \\
\end{array}$ \\
\hline & Sham=GDX & Sham> GDX & $\begin{array}{c}\text { Rats (Kambo \& } \\
\text { Galea, 2006; } \\
\text { Spritzer \& Galea, } \\
\text { 2007) }\end{array}$ & & Sham $>$ OVX & & $\begin{array}{l}\text { Rat (Tanapat et } \\
\text { al., 1999) }\end{array}$ \\
\hline & & $30 \mathrm{~d}$ T > Oil & $\begin{array}{l}\text { Rats (Spritzer \& } \\
\text { Galea, 2007) }\end{array}$ & & $\begin{array}{c}\text { 4h of } \mathrm{E}>\text { Oil } \\
48 \mathrm{~h} \text { of } \mathrm{E}<\text { Oil }\end{array}$ & & $\begin{array}{c}\text { Vole/Rat } \\
\text { (Ormerod \& } \\
\text { Galea, 2001; } \\
\text { Ormerod et al., } \\
\text { 2003) }\end{array}$ \\
\hline & & $30 \mathrm{~d}$ DHT > Oil & $\begin{array}{l}\text { Rats (Spritzer \& } \\
\text { Galea, 2007) }\end{array}$ & & $15 \mathrm{~d}$ of $\mathrm{E}>$ Oil & $15 \mathrm{~d}$ of $\mathrm{E}<\mathrm{Oil}$ & $\begin{array}{c}\text { Barker \& Galea, } \\
2008\end{array}$ \\
\hline
\end{tabular}

* not independent of cell proliferation 
Figure Captions

1. A.) Confocal image of doublecortin-ir cells (green) which are expressed at the border between the granule cell layer and the hilus. B.) A confocal image of neurons labelled with NeuN (green), 28 days after BrdU injection. The white arrow points to a double labelled BrdU (red) and NeuN (green) cell. Note also the s100 $\beta$ cells (blue) are not co-labelled with BrdU in this photo. Scale bar in represents $100 \mu \mathrm{m}$ in B and $50 \mu \mathrm{m}$ in A. C.) An approximate timeline of the maturation of a new neuron in the dentate gyrus from time of injection of DNA synthesis marker, BrdU. The yellow line represents the approximate time period during which Ki-67 would label dividing cells. The light green line represents the approximate time period when doublecortin would be expressed in new immature neurons (from Brown et al., 2003). The dark green line represents the approximate time period during which BrdU-ir cells would also coexpress markers for mature neuronal protein (Brown et al., 2003). Work by Hastings and Gould, 1999 suggests that new neurons are extending their axons rapidly within 4-10 days after birth. Cameron and McKay, 2003 have shown that the cell cycle is approximately $24 \mathrm{~h}$ in rats. These new neurons are electrophysiologically mature within 4 weeks (van Praag et al., 2002) and morphologically mature within 4 months (van Praag et al., 2002). Not drawn to scale. Reprinted with permission from Galea, 2008.

2. The density of BrdU-ir cells in the granule cell layer (GCL) and subgranular zone (SGZ) of the dentate gyrus of adult female rats given BrdU after 26 days of vehicle or antidepressant injections and perfused 24 hours later. Treatment of rats with chronic antidepressants (imipramine) for 26 days significantly increased cell proliferation over control levels in sham $(\mathrm{p} \leq 0.05)$ but not ovariectomized (OVX) female rats. * Significantly different from control 
group (OVX or Sham) $(\mathrm{p} \leq 0.05)$. Sham= intact, $\mathrm{OVX}=$ ovariectomized, $\mathrm{IMI}=$ imipramine. Figure modified from original in Green \& Galea, 2008. 
A

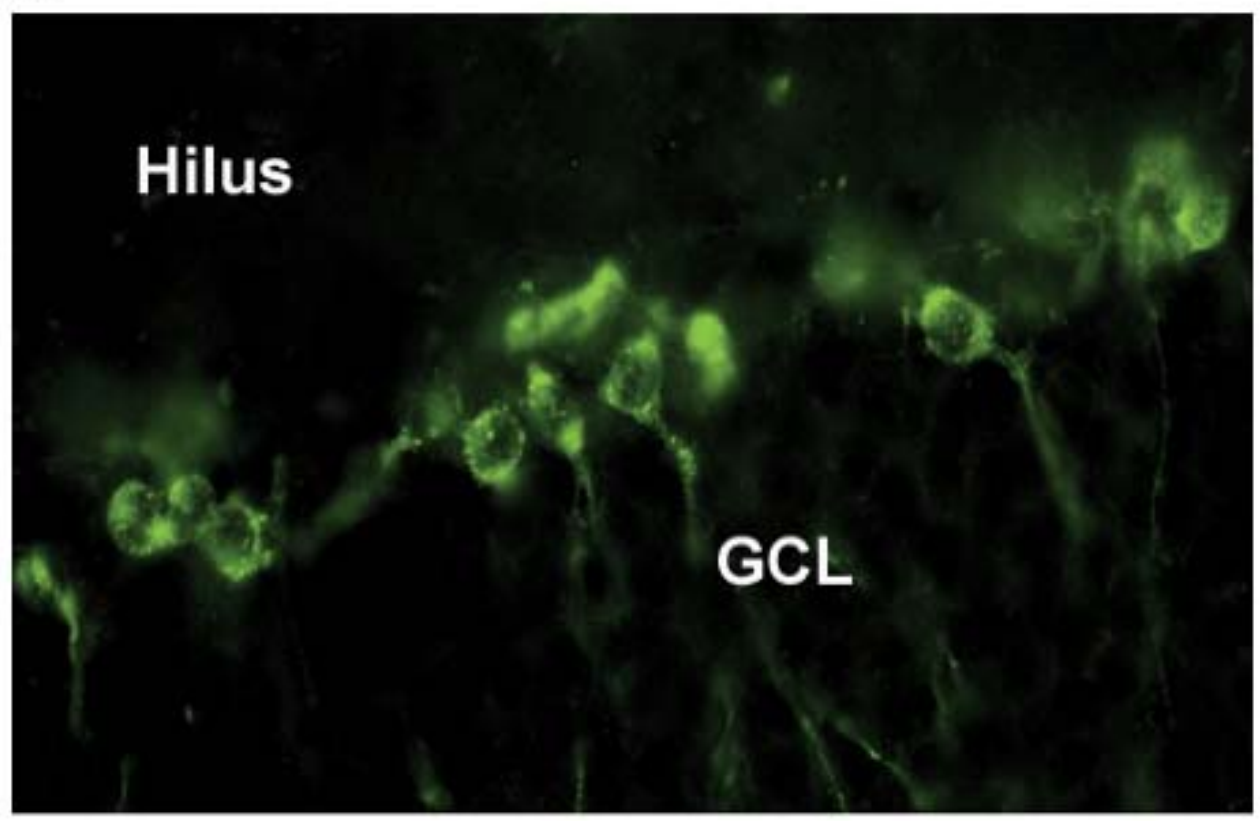

B

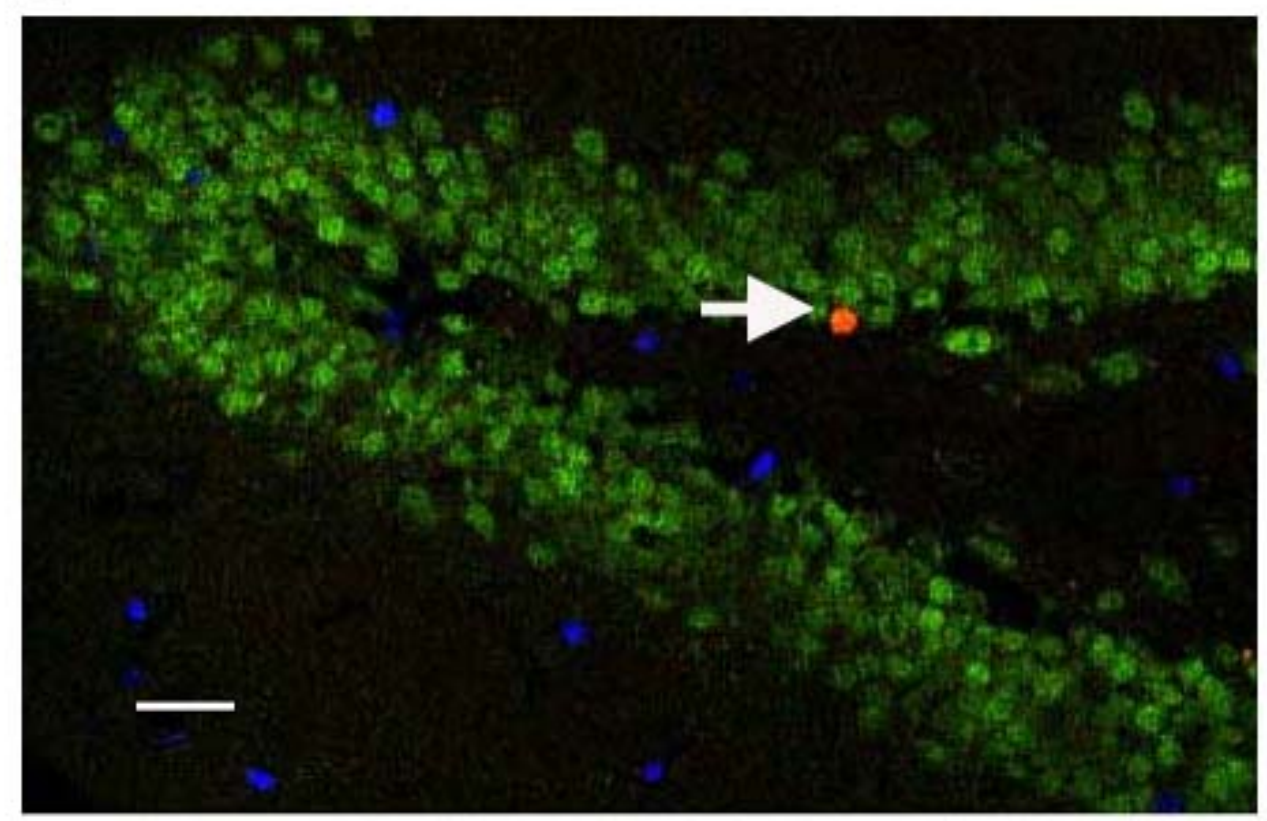

C

\section{BrdU}

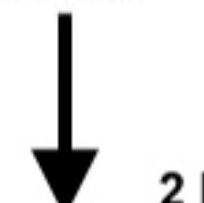

$2 \mathrm{~h}$

$24 \mathrm{~h}$

4-10 d

2-3 wks

4 wks

4 mths+

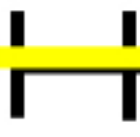

progenitor cells

\section{I}

daughter

cells axons/processes
4

1

begin expressing mature neuronal protein
electrophysiologically mature

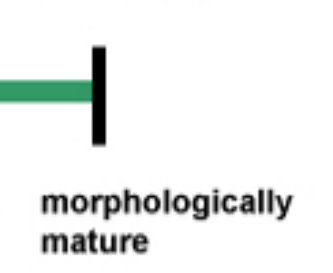




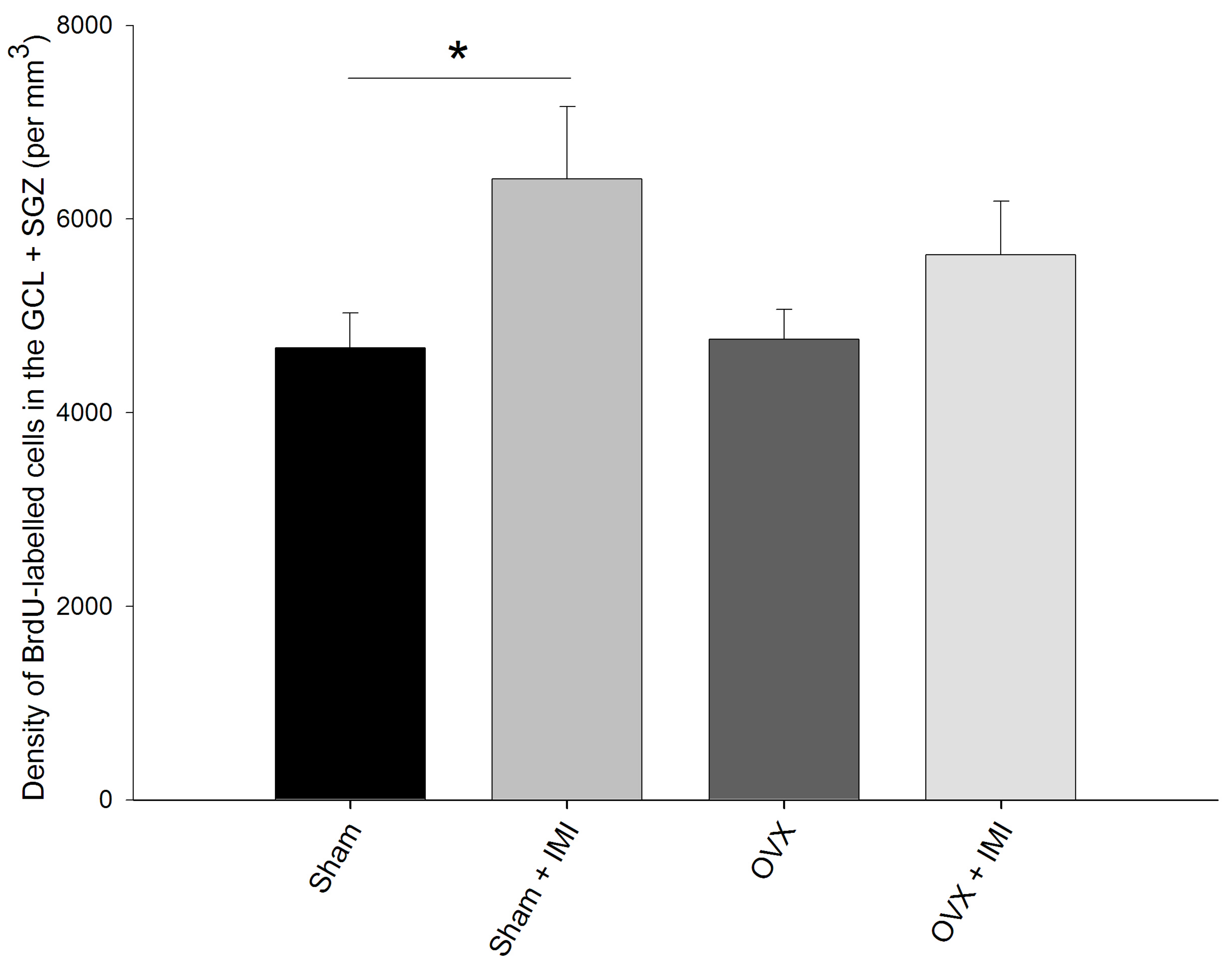

